\title{
Semi-analytical model to predict the performance of cyclic steam stimulation oil wells
}

\author{
George Basta ${ }^{1} \cdot$ Mahmoud Abu El Ela ${ }^{2} \cdot$ Ahmed El-Banbi $^{3} \cdot$ Sayed El-Tayeb ${ }^{2} \cdot$ Saad El-Din Mohamed Desouky ${ }^{4}$. \\ Mohamed Helmy Sayyouh ${ }^{2}$
}

Received: 3 November 2020 / Accepted: 3 February 2021 / Published online: 18 March 2021

(c) The Author(s) 2021

\begin{abstract}
Prediction of the performance of oil wells under Cyclic Steam Stimulation (CSS) is challenging in complex and heterogeneous reservoirs, especially with limited data. Analytical and numerical simulation models do not usually give accurate predictions in such conditions. In this work, a semi-analytical model was developed to determine consistent mathematical relationships between the injected steam and some of the effective oil production parameters for more accurate prediction of oil production rates. Field investigation indicates that the change of the Cumulative Oil to Steam Ratio (COSR) to production days is related to a group of effective oil production parameters. This group of parameters includes the cumulative injected steam relative to the drainage volume, the oil net pay thickness relative to the gross pay thickness, and the vertical permeability relative to the thermal diffusivity. These parameters were arranged in two dimensionless groups. It was found that plotting these two dimensionless groups on Log-Log scale for any reservoir yields a straight line (correlation). For any reservoir under CSS, measurements of two steam cycles are sufficient to identify the constants of the proposed correlation. This method has been applied and validated on six reservoirs with different reservoir characterizations. Six different wells with a total of 43 steam cycles from these reservoirs were analyzed with the same approach. The mathematical relationships of the dimensionless groups were calculated, and the Log-Log plot was constructed for each well using the data of the first two cycles. Then, the proposed correlation was developed for each well and used to predict the well performance starting from the third steam cycle. At the end, the predicted performance of each well was compared with the corresponding actual measurements. The results showed that the average absolute percentage deviation between the actual and the predicted cumulative oil production through the well lifetime is less than $5 \%$ for the six wells. In addition, the absolute instantaneous deviation between the actual and the predicted cumulative oil production for each individual cycle in all cases is (1) less than $15 \%$ for about $42 \%$ of the tested CSS cycles, (2) between 15 to $25 \%$ for about $39 \%$ of the tested CSS cycles, and (3) higher than $25 \%$ for about $19 \%$ of the tested CSS cycles. This work is considered an original contribution to develop dimensionless relationships that can be used to predict the oil production of the CSS operations for reservoirs with limited data. The required data are the historical production rate, steam injection rate, and basic petrophysical parameters.
\end{abstract}

Keywords Cyclic Steam Stimulation · Performance Prediction of the CSS Wells · Heavy Oil · Thermal EOR · Thermal Enhanced Oil Recovery · CSS Field Applications

Mahmoud Abu El Ela

m.ella@cu.edu.eg

George Basta

george-basta@live.com

Ahmed El-Banbi

ahmed.elbanbi@aucegypt.edu

Sayed El-Tayeb

sayed_eltayeb6262@yahoo.com

Saad El-Din Mohamed Desouky

usdesouky@yahoo.com

\author{
Mohamed Helmy Sayyouh \\ sayyouh@gmail.com \\ 1 Scimitar Production Egypt Ltd. (SPEL), Cairo, Egypt \\ 2 Cairo University, Giza, Egypt \\ 3 The American University in Cairo, Cairo, Egypt \\ 4 Egyptian Petroleum Research Institute, Cairo, Egypt
}




\section{Abbreviations}

$\begin{array}{ll}\text { APD } & \text { Absolute Percentage Deviation } \\ \text { COSR } & \text { Cumulative Oil to Steam Ratio (STB/STB) } \\ \text { CSS } & \text { Cyclic Steam Stimulation } \\ \text { CWE } & \text { Cold Water Equivalent } \\ \text { EOS } & \text { Equation of State } \\ \text { USA } & \text { United States of America } \\ \text { List of symbols } \\ h & \text { Gross pay thickness, } \mathrm{ft} \\ R & \text { Drainage radius, ft } \\ V & \text { Drainage volume, bbl } \\ \mathrm{X} & \left(\left(\frac{\text { Injected Steam Volume [bbl] }}{\text { Drainage Volume [ bbl] }}\right) *\left(\frac{\text { Net Pay Thickness }(\mathrm{ft})}{\text { Gross Pay Thickness }(\mathrm{ft})}\right)\right) \\ \mathrm{Y} & \left(\left(\frac{\text { CosR }(\text { Cum. Oil } / \text { Cum. Steam })\left[\frac{\text { sTB }}{\text { STB }}\right]}{\text { Production Days [ Days] }}\right) *\right.\end{array}$

\section{Introduction}

Conventional oil resources are estimated at only $30 \%$ of the total worldwide oil resources, while all other viscous oil including heavy oil, extra heavy oil, bitumen, and oil sand make up the remaining 70\% (Finbow and Koop 1978). The CSS has proved its effectiveness as a thermal enhanced oil recovery method in several heavy oil reservoirs with different reservoir characteristics (Basta 2020; Failed 2013). CSS oil production predictive tools are essential requirements to manage reservoirs under CSS (Yang et al. 2014). Generally, there are three categories of methods of CSS oil production prediction: analytical models, numerical simulation, or analogy methods (Abou-Kassem 1996).

The analytical predictive models use different assumptions to simplify the calculations of oil production prediction. The assumptions affect the accuracy of the analytical models (Yang et al. 2014). Several predictive models have been developed for different conditions and assumptions. The first published model assumed that the reservoir is pressurized with a drive mechanism, but generally the CSS is applied in depleted reservoirs with low reservoir pressure (Abu El Ela et al. 2008). Later, several other analytical models were developed to take the effects of the depleted reservoirs and gravity derange into consideration (Ali and Tamin 1998; Alvarez and Sungyun 2013; Boberg and Lantz 1966).

Most analytical models had a limiting assumption which is that steam forms a cylinder in the reservoir at the end of the steam injection period. However, field observation shows that steam goes to the top zone or into highly permeable zones (Jones 1992). Therefore, in 1984, Gontijo and Aziz developed a model that considered a conical steam shape (Mueller 1967). In 1998, Ali and Tamin developed a model to take into consideration the vertical fractures which were created and surrounded the wellbore after steam injection (Mozaffari et al. 2013).

In 1967, Mueller developed a numerical simulation model for the CSS applications (Rivero and Heintz 1975). This model used the finite element algorithm to predict the CSS oil production. The model assumed that the reservoir under study was homogeneous with radial heat transfer and symmetrical flow around the wellbore. In addition, effects of capillary and gravitational forces were taken into consideration. This initial model could predict the average reservoir performance versus time. Afterward, the model was developed to consider two-dimensional and three-phase flow. Later, it was developed for three-dimensional problems. It should be highlighted that the dissolved gas and steam distillation were taken into consideration for oil production prediction of the CSS by numerical simulation approach (Finbow and Koop 1978).

Subsequently, another numerical simulation model was developed to predict the CSS oil production from fractured carbonate reservoir by Biggs in 1989 (Sun and Ertekin (2016)). In this study, three-phase, three-dimensional, fully implicit, compositional simulator was built. This simulator was developed to use different correlations to predict the change in the relative permeability curves with the application of the CSS. In 2013, Mozaffari et al. developed a numerical simulation model to solve the mass and energy balance for the steam injection in heavy oil reservoirs (Towson and Boberg 1967). Generally, difficulties exist in using the numerical simulation models in cyclic steam injection applications at the primary stage of production. These difficulties are related to the sensitivity of the thermal simulation models to the rock and fluid properties and the geological characterization. Usually, this information has high degree of uncertainty in the heterogeneous reservoirs (Yoelin 1971). As highlighted by Abou-Kassem (1996) and Tamim et al. (2000), the numerical simulation is sensitive to the accuracy of the representing Equation of State (EOS) of the crude oil. They clarified that the accuracy of the thermal numerical simulation is affected by the grid refinement and the grid orientation which directly affect the steam movement (Esmaeili et al. 2019; Faergestad 2016). In an attempt to improve numerical simulation predictions, in 2019, Esmaeili et al. developed a data-driven model to predict the effect of temperature on water-oil relative permeability (Failed 1983). Also, in 2019, Marquez et al. studied the effect of the temperature-dependent relative permeabilities on simulation results using data of a heavy oil reservoir in the Middle East (Failed 1984). In 2016, Sun and Turgay developed an artificial intelligence model to predict the oil production in 
the CSS processes (Jones 1977). The model was verified and tested using data of a homogenous sandstone reservoir.

On the other hand, the analogy relationships in the CSS applications for specific reservoirs are built using historical data for the parameters which have impact on the oil production rates or the cumulative oil production. The established relationships in the analogy approach can be used to predict the oil wells performance in the same reservoir. Several different approaches were published to develop effective prediction relationships (Yang et al. 2014; Popa and Patel 2012; Uribe et al. 2010; Failed 1995). These methods aimed to find direct relationships between one of the effective parameters and oil production rate. However, till now, there is no effective approach in the previous trials because the developed methods failed to define a general formula or correlation suitable for all reservoirs. The previous methods also ignored the deterioration of the level of interaction between steam injection and oil production from one steam cycle to another. This interaction changes due to the hysteresis effect from injection and production phases in addition to the changes of the reservoir temperature from one steam cycle to another. This paper presents a semi-analytical model to predict the oil wells performance under the CSS applications using limited input data.

\section{Features of the developed model}

\section{Main concepts of the model}

The main idea of the developed model is to define which parameters are important in predicting oil production in different CSS cycles, and to identify mathematical relationships between those effective parameters and the CSS oil production. A large database of wells undergoing CSS was used empirically to identify which parameters are the most important in predicting oil production rates. The oil production by CSS depends on the interaction between steam, oil, and rock. The heat efficiency-related parameters as well as the net pay thickness relative to the reservoir gross pay thickness along with the steam injection rates were considered in the mathematical relationships. These parameters are different from well to well and have impact on the oil production rates of the wells.

Actual CSS well data were used to identify the general forms of the expected mathematical relationships. The data were collected from an oil well (Well 1-1) from Upper Dolomite reservoir-Issaran field (Egypt). Upper Dolomite reservoir is characterized by heterogenous reservoir properties. Several different mathematical relationships were tried and tested with the available data in different forms. The best mathematical relationship that relates oil production with simple reservoir and operations parameters was obtained, when (1) the effective parameters were arranged into two dimensionless terms as shown in Eqs. (1) and (2), and (2)the two terms in Eqs. (1) and (2) were plotted in Log-Log plot.

$$
\begin{aligned}
X= & \left(\left(\frac{\text { Injected Steam Volume }[\mathrm{bbl}]}{\text { Drainage Volume }[\mathrm{bbl}]}\right)\right. \\
& \left.*\left(\frac{\text { Net Pay Thickness }(\mathrm{ft})}{\text { Gross Pay Thickness }(\mathrm{ft})}\right)\right) \\
Y= & \left(\left(\frac{\operatorname{COSR}(\text { Cum. Oil } / \text { Cum. Steam })\left[\frac{\text { STB }}{\text { STB }}\right]}{\text { Production Days }[\text { Days }]}\right)\right. \\
& \left.*\left(\frac{\text { Vertical Permeability }[\text { Darcy }]}{\text { Thermal Diffusivity }\left[\frac{\mathrm{ft} 2}{\text { Days }}\right]}\right)\right)
\end{aligned}
$$

The drainage volume can be calculated per each well according to Eq. (3).

$V=\left(\frac{1}{5.615} * \pi R^{2} *[h]\right) \mathrm{bbl}$

where $R$ drainage radius of the well (ft), $h$ gross pay thickness (ft), COSR Cumulative Oil Production to Cumulative Steam Injection Ratio (STB/ STB).

The Log-Log plot between $X$ and $Y$ Functions provided a straight line with a general mathematical form as shown in Eq. (4).

$Y=a X^{-b}$

where $a$ and $b$ are constants in the general mathematical form (correlation). They can be obtained from the Log-Log plot. These constants are changed from well to well. They might account the effects of the other parameters which are not mentioned in $X$ and $Y$ functions such as lateral permeability, relative permeability, oil viscosity, and wettability.

The mathematical relationships of Eqs. (1) and (2) depend on the rate of change of the COSR (Cumulative Oil Production to Cumulative Steam Injection Ratio) per day of production from cycle to cycle. The term of COSR per days of production is related to four effective parameters. It is directly proportional to three parameters: (1) the ratio of the heated zone volume relative to the drainage volume; (2) the ratio of the net pay thickness relative to the gross pay thickness; and (3) the thermal diffusivity. In addition, it is inversely proportional to the heat losses, which are directly proportional to the vertical permeability to overburden and underburned rocks.

It should be highlighted that the terms of Eqs. (1) and (2) can be identified with minimum available data. The 
oil production and steam injection data are usually readily available. The oil production data include oil production rates and days on production which can be extracted from the daily production reports. The steam injection data include the cumulative injected steam per each steam cycle which can be extracted from the daily injection reports. The reservoir net pay thickness and gross pay thickness can be extracted from the petrophysical log interpretation of the well under study. The vertical permeability can be usually extracted from core analysis reports. Thermal diffusivity can be obtained from published values depending on lithology. For sandstone and carbonate reservoirs, thermal diffusivity is equal to $2.15 \times 10^{-6} \mathrm{~m}^{2} / \mathrm{s}\left(1.99 \mathrm{ft}^{2} /\right.$ Day $)$ and $1.96 \times 10^{-6} \mathrm{~m}^{2} / \mathrm{s}\left(1.82 \mathrm{ft}^{2} /\right.$ Day), respectively (Basta 2020).

It should be highlighted that the two dimensionless terms $X$ and $Y$ were obtained after several different mathematical forms were tried and tested with the available data (trial and error process) to get the best mathematical relationship that relates oil production with the reservoir and operations parameters. Although the developed relationship is presented in a simple form, it includes mass and heat balance parameters. The mass balance parameters can be considered in the volume of the cumulative steam injected, the volume of the cumulative oil production, and the estimated drainage volume. However, the heat balance parameters can be counted in the thermal diffusivity rate and two heat losses factors. The thermal diffusivity rate is defined as the thermal conductivity divided by the density and the specific volumetric heat capacity. However, the first heat losses factor is the heat losses inside the reservoir due to the existence of non-productive layers such as shale or anhydrite. This factor is a function of the ratio of the net pay thickness relative to the gross pay thickness. While the second heat losses factor is the heat losses due to the heat flow from the producing layers into the overburden and the underburned rocks. This factor is a function of the vertical permeability.

\section{Testing of the approach}

The developed relationships of Eqs. (1) and (2) were tested using the CSS data of Well 1-1 (Upper Dolomite

Table 1 Main properties and conditions of the field applications

\begin{tabular}{|c|c|c|c|c|c|c|c|}
\hline & Unit & $\begin{array}{l}\text { Upper Dolomite } \\
\text { reservoir-Issaran } \\
\text { field }\end{array}$ & $\begin{array}{l}\text { Buffalo Creek } \\
\text { reservoir-Gros- } \\
\text { mont formation }\end{array}$ & $\begin{array}{l}\text { Diatomite } \\
\text { reservoir-Orcutt } \\
\text { oil field }\end{array}$ & $\begin{array}{l}\text { Tar Sand reser- } \\
\text { voir-Huntington } \\
\text { Beach field }\end{array}$ & $\begin{array}{l}\text { Well } 8 \text { Sec- } \\
\text { tion } 25 \\
\text { formation-Kern } \\
\text { River field }\end{array}$ & $\begin{array}{l}\text { Buena Fe Fee } \\
\text { lease - Midway } \\
\text { Sunset field }\end{array}$ \\
\hline $\begin{array}{l}\text { Estimated origi- } \\
\text { nal oil in place }\end{array}$ & STB & $1.1 \times 10^{9}$ & $145 \times 10^{6}$ & $2 \times 10^{9}$ & $338 \times 10^{6}$ & $3.1 \times 10^{9}$ & $34.1 \times 10^{6}$ \\
\hline $\begin{array}{l}\text { Reservoir aver- } \\
\text { age depth }\end{array}$ & $\mathrm{ft}$ & $850-1000$ & $400-600$ & 1700-2000 & 1500-2000 & $750-1300$ & $600-1500$ \\
\hline $\begin{array}{l}\text { Average initial } \\
\text { water satura- } \\
\text { tion }\end{array}$ & $\%$ & 30 & 15 & 35 & 21 & 20 & 25 \\
\hline Average porosity & $\%$ & 35 & 25 & 24 & 35 & 35 & 34 \\
\hline $\begin{array}{l}\text { Average reser- } \\
\text { voir perme- } \\
\text { ability }\end{array}$ & $\mathrm{mD}$ & $10-35$ & $10-200$ & $<10$ & $400-800$ & $3000-4000$ & 2000 \\
\hline $\begin{array}{l}\text { Oil net pay thick- } \\
\text { ness }\end{array}$ & $\mathrm{ft}$ & 150 & $50-80$ & 125 & $40-58$ & 190 & 205 \\
\hline $\begin{array}{l}\text { Gross reservoir } \\
\text { thickness }\end{array}$ & $\mathrm{ft}$ & 400 & $100-200$ & 500 & 115 & 210 & $300-500$ \\
\hline $\begin{array}{l}\text { Reservoir dip } \\
\text { angle }\end{array}$ & degrees & 5 & 4 & 5 & $<3$ & 4 & up to $70^{\circ}$ \\
\hline $\begin{array}{l}\text { Initial reservoir } \\
\text { pressure }\end{array}$ & psi & 500 & 150 & 350 & 935 & 225 & $<500$ \\
\hline $\begin{array}{l}\text { Initial reservoir } \\
\text { temperature }\end{array}$ & ${ }^{\circ} \mathrm{F}$ & 100 & 70 & 100 & 127 & 80 & 90 \\
\hline $\begin{array}{l}\text { Oil viscosity at } \\
\text { standard condi- } \\
\text { tions }\end{array}$ & $\mathrm{cP}$ & 4000 & $>100,000$ & 1000 & 11,000 & 4000 & 1500 \\
\hline $\begin{array}{l}\text { Oil formation } \\
\text { volume factor }\end{array}$ & rbbl/ STB & 1.05 & 1.03 & 1.04 & 1.033 & 1.05 & 1.06 \\
\hline Oil gravity & ${ }^{\circ} \mathrm{API}$ & $10-12$ & 7 & 12 & $12-15$ & 14 & 12 \\
\hline
\end{tabular}




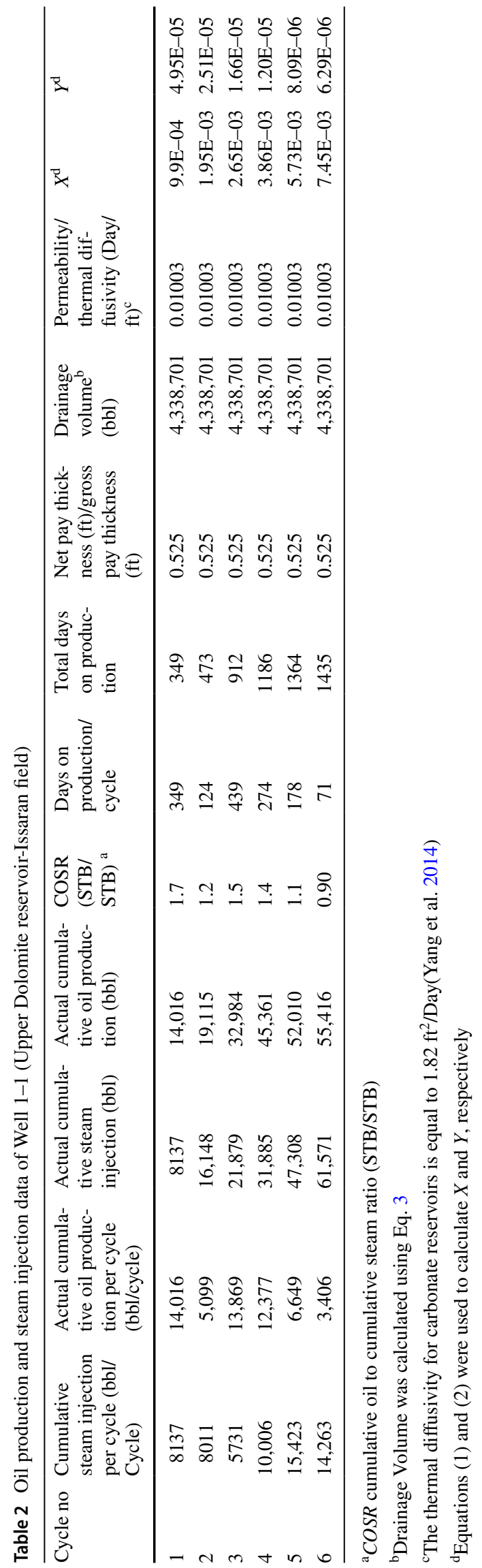

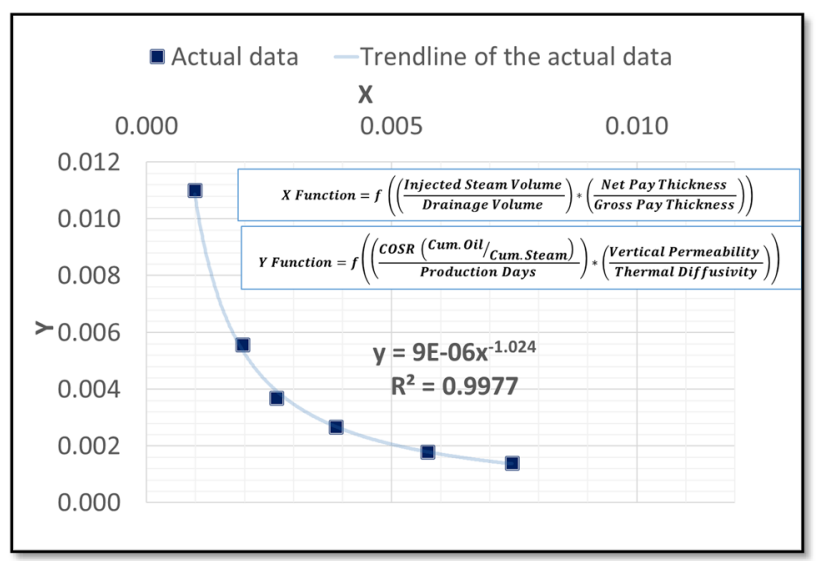

Fig. 1 The mathematical relationship on Cartesian scale for Well 1-1

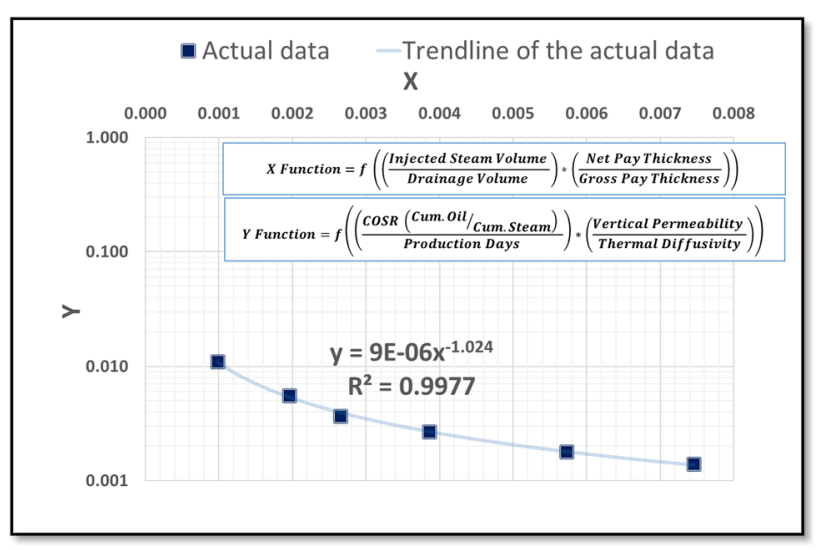

Fig. 2 The mathematical relationship on Semi-Log scale for Well 1-1

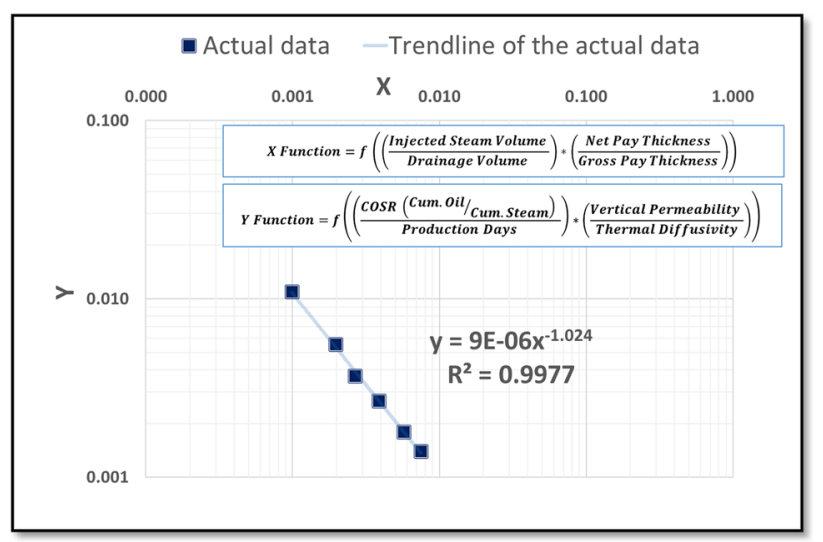

Fig. 3 The mathematical relationship on Log-Log scale for Well 1-1

reservoir-Issaran field-Egypt). Table 1 summarizes the main parameters and properties of the Upper Dolomite reservoir. Table 2 presents the oil production and steam injection data of Well 1-1. Table 2 presents the data which 
were used to build the mathematical relationships of $X$ and $Y$ functions (Failed 2013). Figures 1, 2 and 3 present the relationship between $X$ and $Y$ functions on Cartesian, Semi$\log$, and $\log -\log$ scale; respectively. Plotting the two terms on $\log -\log$ scale shows a linear relation between $X$ and $Y$ functions. The approach of plotting $Y$ versus $X$ functions was tested using actual data of several wells. In all cases, a straight line was formed on the $\log -\log$ scale.

The approach indicates that the Log-Log relationship can be developed for each well using data of only two steam cycles. Then, this linear relationship (on Log-Log scale) can be used to predict the oil production of the CSS for future cycles. For a new CSS oil production prediction, the $X$ function can be estimated by Eq. (1) and using the proposed cumulative steam injection. Then, the corresponding point in $Y$ axis can be identified and used to predict the oil production by defining the total days on production at the end of each steam cycle.

\section{Steps of the approach}

The methodology which can be used to develop the mathematical relationship for any CSS well includes the following steps:

1. Identify the petrophysical parameters: net pay thickness, gross pay thicknesses, and vertical permeability.

2. Estimate the drainage volume of the well from Eq. (3).

3. Estimate the thermal diffusivity according to the type of the reservoir rock.

4. Collect data of two steam cycles: the production and injection data are collected at (1) the end of the first steam cycle, and (2) any time at the second steam cycle. The main parameters at each point are the cumulative oil production, total days on production, and cumulative injected steam.

5. Calculate the main terms of the mathematical relationship ( $X$ and $Y$ functions) using Eqs. (1) and (2) for the selected two cycles.

6. Develop the Log-Log plot and identify the straight line on the plot.

7. Extrapolate the Log-Log relationship for the CSS oil production prediction.

8. Identify the form and the constants of the mathematical relationship between $\mathrm{X}$ and $\mathrm{Y}$ functions using the Log-Log plot (Eq. 4)

9. For prediction of oil production in a new cycle, $X$ function is estimated using Eq. (1) and considering the cumulative steam injection. Then, the corresponding point in $Y$ axis is determined using Eq. (4) or the developed Log-Log plot. Then, the value of $Y$ term can be identified and used to back-calculate the oil production by defining the total days on production at the end of each steam cycle.

\section{Validation of the model using field applications}

Data of six more CSS wells were collected from six CSS reservoirs of different conditions. The collected data include data of another well (Well 1-2) from the CSS project at the Upper Dolomite reservoir of Issaran field (Egypt). The other five wells (Well 2, Well 3, Well 4, Well 5, and Well 6) belong to different reservoirs: Buffalo Creek reservoir of Grossmont formation (Canada), Diatomite reservoir of Orcutt Oil field (USA), Tar Sand reservoir of Huntington Beach field (USA), Section 25 of Kern River field (UAS), and Buena Fe Fee Lease of Midway Sunset field (USA); respectively. They represent variation of reservoir properties, rock types, and operations conditions.

The Upper Dolomite reservoir of Issaran field and Buffalo Creek reservoir of Grossmont formation are fractured carbonate reservoirs (Basta 2020; Failed 2013). However, Diatomite reservoir of Orcutt oil field includes tight matrix (Abou-Kassem 1996). On the other hand, the Tar Sand reservoir of Huntington Beach field is unconsolidated sandstone with thin interbedded shale (Abu El Ela et al. 2008). Section 25 of Kern River field is a layered sandstone reservoir (Ali and Tamin 1998). Finally, the CSS data of Buena Fe Fee Lease of Midway Sunset field represent sandstone reservoir with high dip angle reaching up to $70^{\circ}$ (Alvarez and Sungyun (2013)).

Table 1 presents the main properties and conditions of the six fields. Table 1 indicates that the studied reservoirs have different reservoir depths. Buffalo Creek reservoir depth is $400 \mathrm{ft}$, while Diatomite and Tar sand reservoirs reach $2000 \mathrm{ft}$. Also, the initial water saturation varies from 24 to $35 \%$. Table 1 also shows a wide variation in the reservoir permeability for the six reservoirs. The Diatomite reservoir is very tight matrix with a permeability less than $10 \mathrm{mD}$, while Section 25-Kern River field is unconsolidated reservoir with a permeability greater than $3,000 \mathrm{mD}$. In addition, the average reservoir net pay thickness ranges from 40 to $205 \mathrm{ft}$. Also, the reservoir dip angle varies for the selected reservoirs. Tar Sand reservoir has dip angle less than $3^{\circ}$, while Buena Fe Fee Lease has dip angle up to $70^{\circ}$. Table 1 indicates variation in oil viscosity. The viscosity ranges between $1000 \mathrm{cP}$ to greater than $100,000 \mathrm{cP}$. This variety in reservoir properties supports the applicability of the developed model to wide range of reservoirs under CSS.

Table 3 presents the oil production and steam injection data at the end of the first and second cycles for the six wells (Well 1-2, Well 2, Well 3, Well 4, Well 5 and Well 6). The developed model was applied on the available data of the 


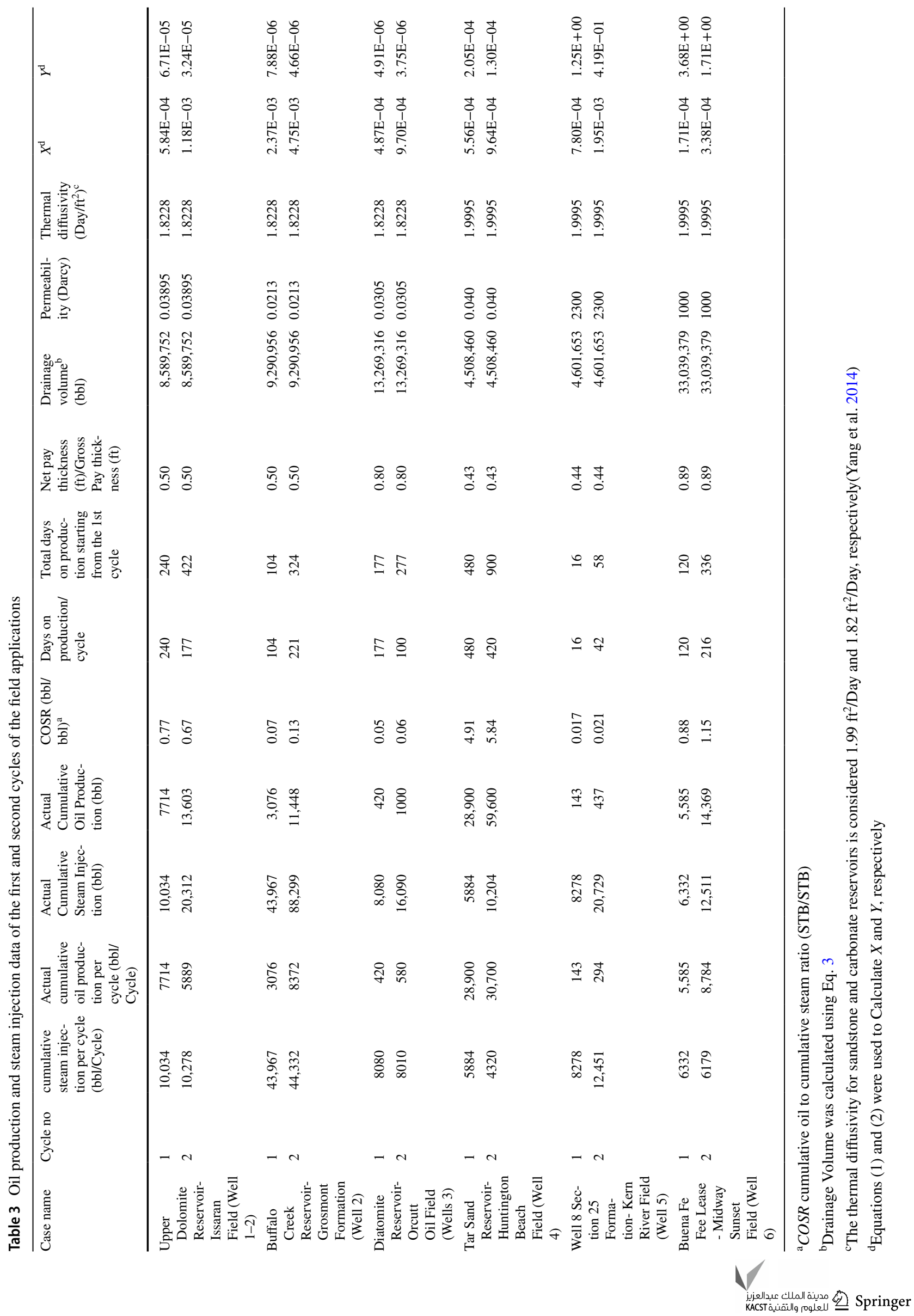




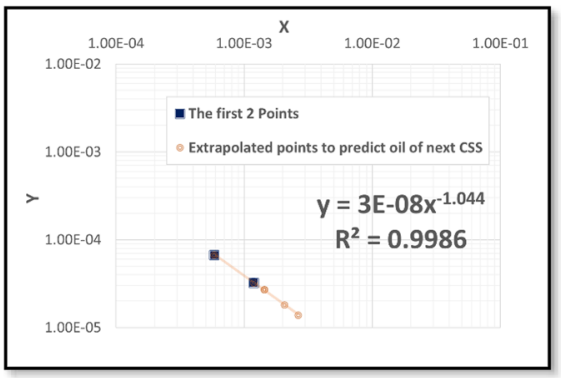

A Well 1.2 -Upper Dolomite reservoir-Issaran field

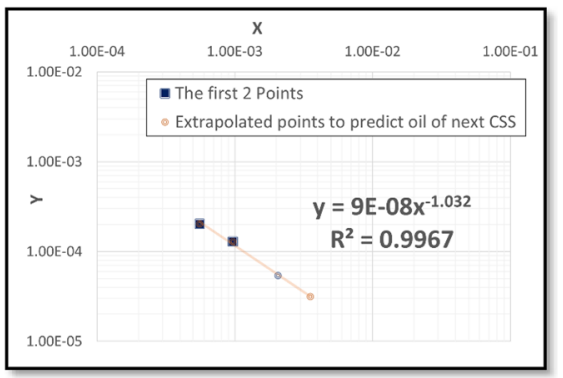

D Well 4 - Tar Sand reservoir- Huntington field

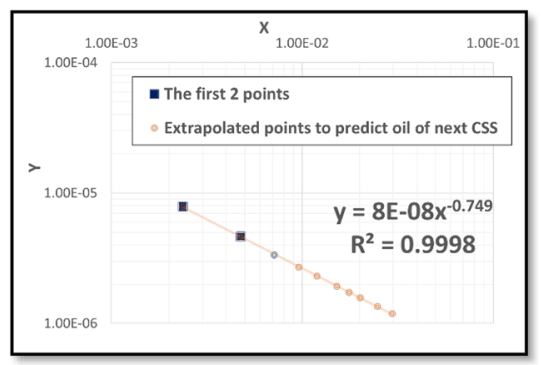

B Well 2- Buffalo Creek reservoir-Grosmont formation

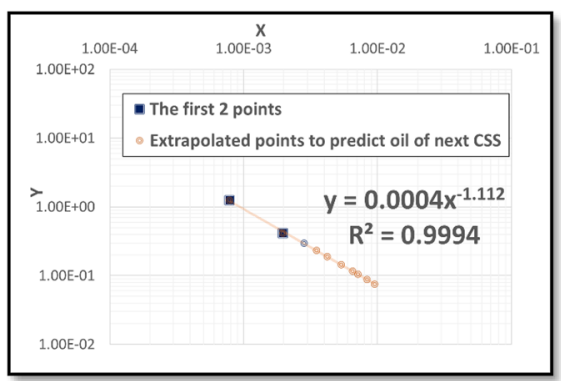

E Well 5 - Section 25-Kern River field

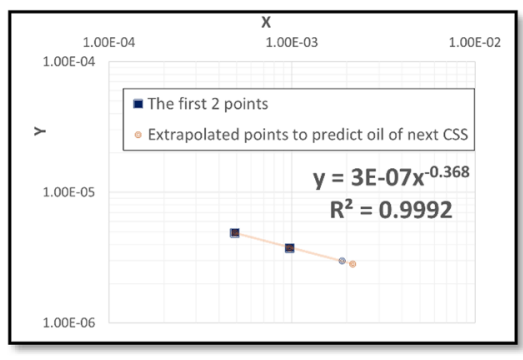

C Well 3- Diatomite reservoir- Orcutt Oil field

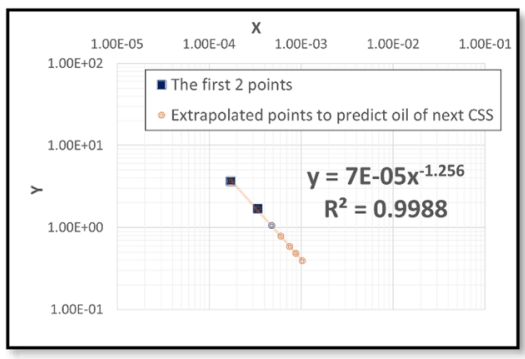

F Well 6 - Buena Fe Fee Lease -Midway Sunset field

Fig. 4 Log-Log plots of the six wells

six wells. Table 3 also presents the calculations of the $X$ and $Y$ functions according to (1) Eqs. (1) and (2) and (2) the reservoirs data which is presented in Table 1 . The data of the first two cycles in each well enabled us to obtain the change in the COSR (Cumulative Oil to Cumulative Steam Ratio) per production days. The different reservoirs show different values of the change of the COSR (Cumulative Oil Steam Ratio) with days on production.

The calculated $X$ and $Y$ functions of the first two cycles of each of the six wells (Table 3) were used to develop the corresponding Log-Log plots. Figure 4 shows the developed correlation of the established mathematical relationship on the Log-Log plots of each well in the six reservoirs, and its extrapolation. In addition, Table 4 summarizes the calculations of the oil production prediction starting from the $3 \mathrm{rd}$ cycle for each well. Table 4 presents the actual cumulative steam injection of each cycle of the six wells. The actual cumulative steam injection values at each cycle in each well was used to calculate the $X$ function at the end of each cycle using Eq. (1). Then, the corresponding value of the $Y$ function was extracted at each cycle using the extrapolated Log-Log relationship for each well (Fig. 4). After that, the oil production was calculated using Eq. (2) and the corresponding $Y$ function at each cycle for each well. As shown in Fig. 4, there is a unique slope for the line in each case due to the change in the COSR per production days for each case. This change is achieved according to the variation in the petrophysical parameters, type of the rock, and the heat efficiency (e.g., the parameters of Eqs. (1) and (2)).

\section{Results of the validation}

Table 5, Fig. 5 and Fig. 6 present comparisons between the predicted and actual cumulative oil production performance at each cycle for each well. These comparisons were performed through the well lifetime per each steam cycle. There is a good match between the calculated and the actual oil production in all cases even in the well that has 13 steam cycles. Table 5 presents also the average absolute percentage deviation between the actual and predicted CSS oil production to quantify the validity of the developed model. The deviation percentage was calculated using Eq. (5).

The Absolute Percentage Deviation(APD)

$$
=\left[\frac{(\text { Actual Cum. Oil }- \text { Calculated Cum. Oil })}{\text { Actual Cum. Oil }}\right] \%
$$

Table 5 presents the absolute percentage deviation between the actual and predicted cumulative CSS oil production for each well at different conditions: (1) at each specific steam cycle and (2) through the well lifetime. It should be highlighted that the first two cycles of each well were excluded from the validation as the data of the first 


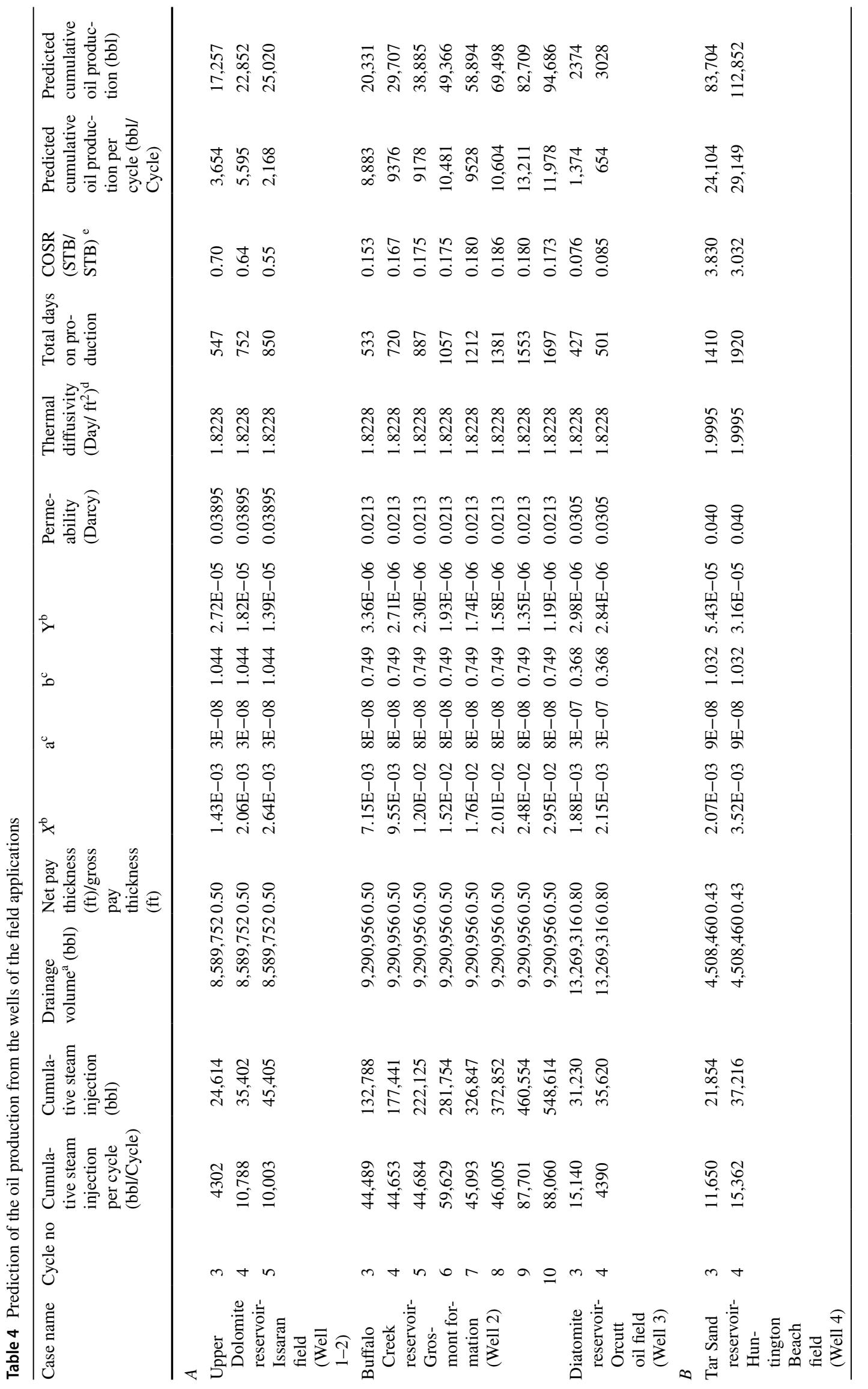




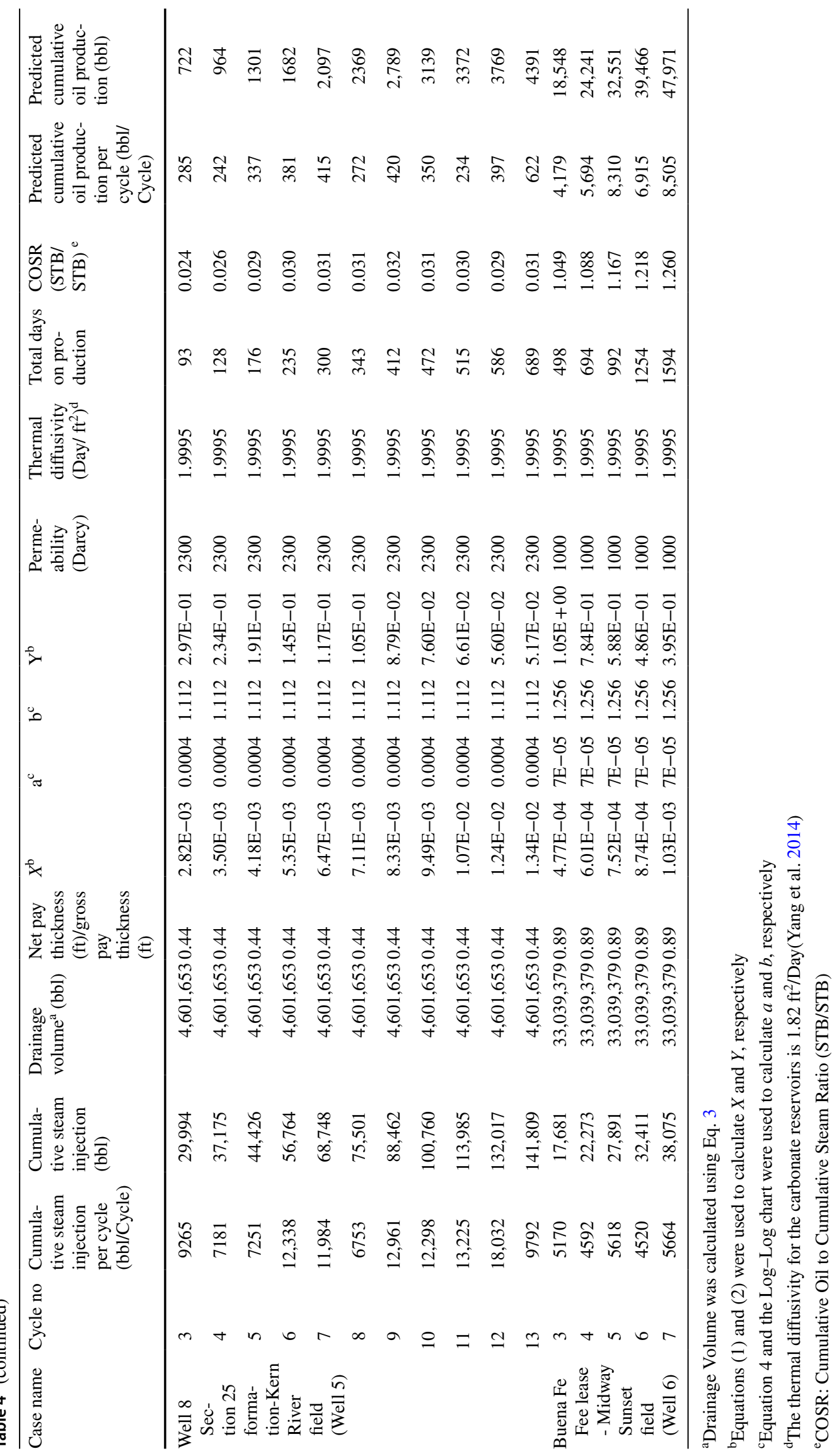




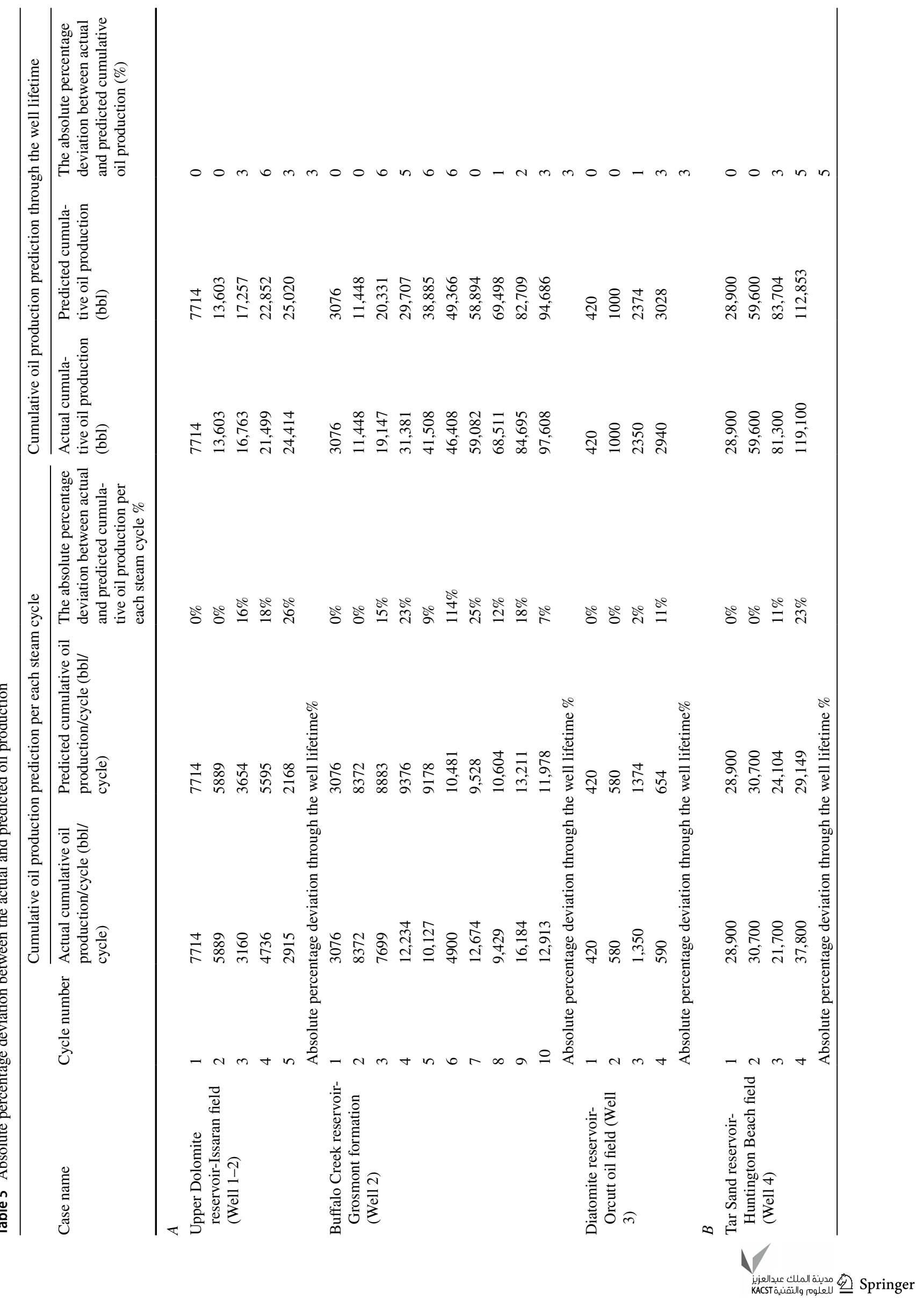




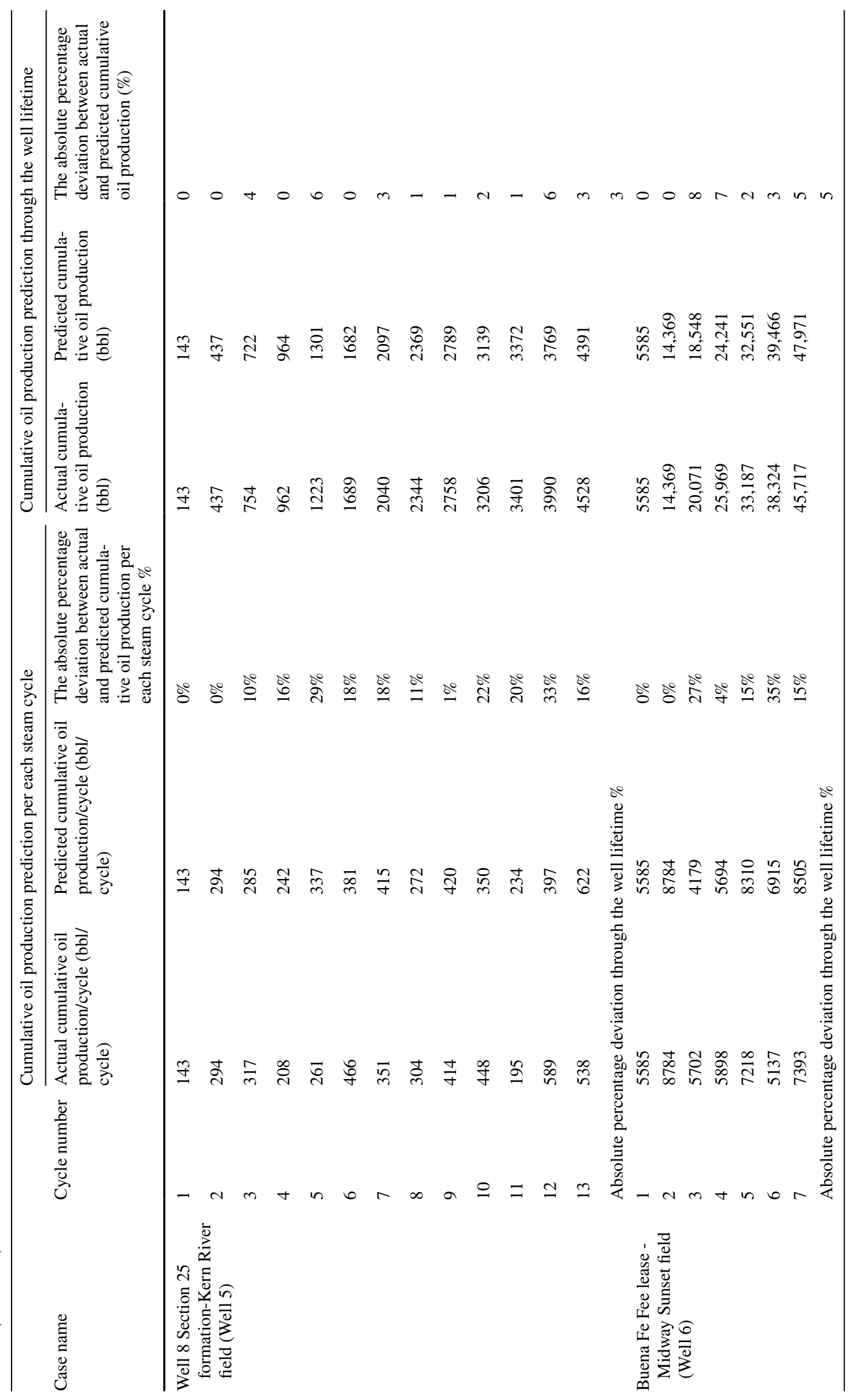




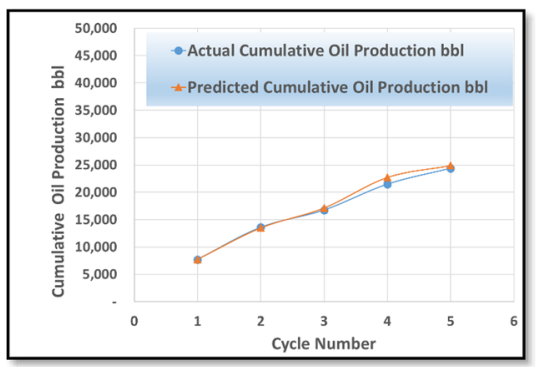

A Well 1.2 -Upper Dolomite reservoir-Issaran field

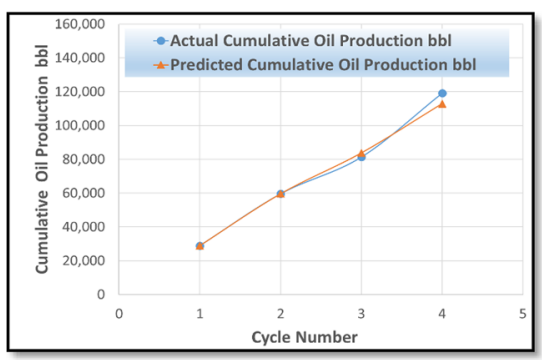

D Well 4 - Tar Sand reservoir- Huntington field

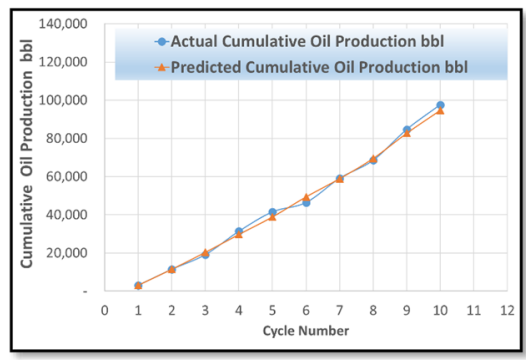

B Well 2- Buffalo Creek reservoir-Grosmont formation

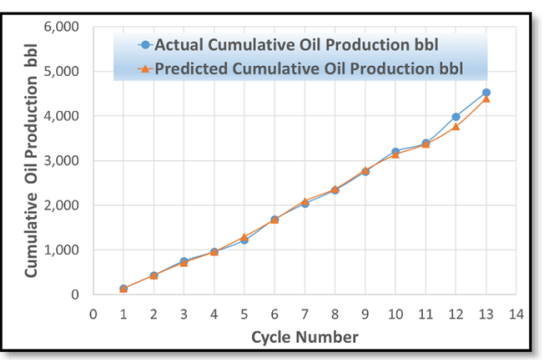

E Well 5 -Section 25-Kern River field

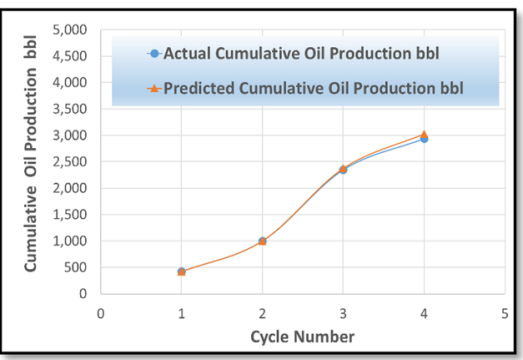

C Well 3-Diatomite reservoir- Orcutt Oil field

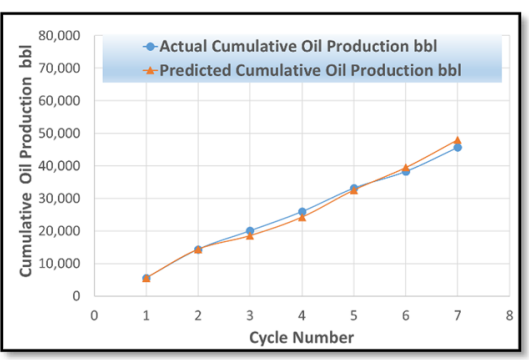

F Well 6 - Buena Fe Fee Lease -Midway Sunset field

Fig. 5 Comparisons between the actual and predicted cumulative oil production through well lifetime

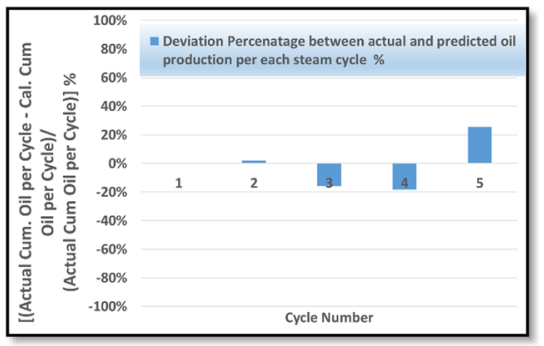

A Well 1.2- Upper Dolomite reservoir-Issaran field

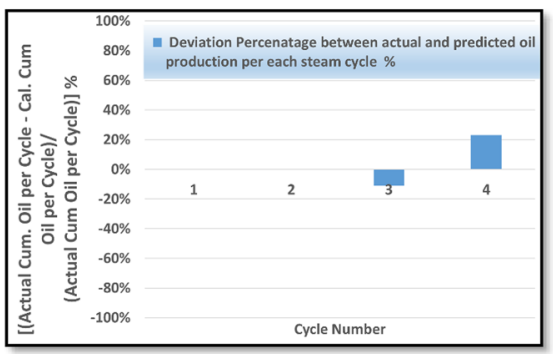

D Well 4 - Tar Sand reservoir- Huntington field

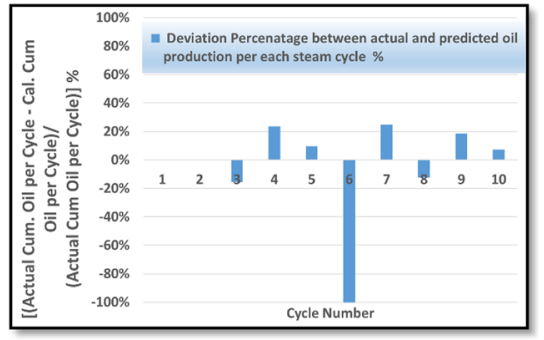

B Well 2- Buffalo Creek reservoir-Grosmont formation

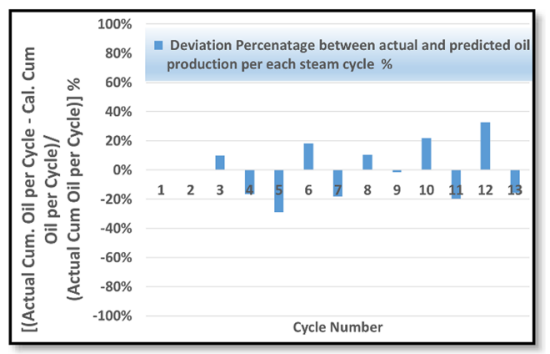

E Well 5 -Section 25-Kern River field

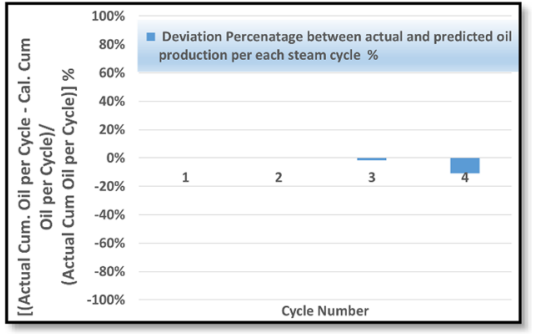

C Well 3- Diatomite reservoir- Orcutt Oil field

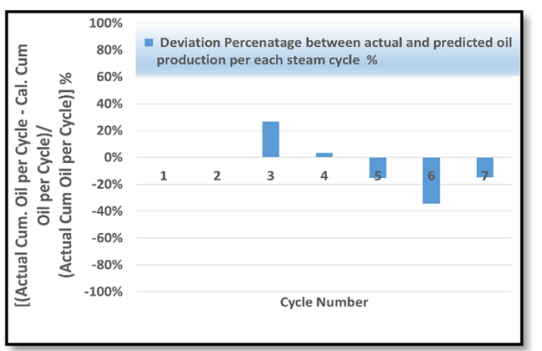

F Well 6 -Buena Fe Fee Lease -Midway Sunset field

Fig. 6 Deviation percentage between the actual and predicted cumulative oil production per each steam cycle

two steam cycles were used to develop the corresponding relationship of each well as presented in Table 3 and Fig. 4. As presented in Tables 4 and 5, the prediction was carried out starting from the third cycle of each well. Accordingly, the developed mathematical relationships predicted 31 steam cycles out of the 43 steam cycles related to the six wells.

As illustrated in Table 5 and Fig. 5, it is clear that the maximum absolute percentage deviation between the actual and predicted cumulative CSS oil production for each well through its lifetime is less than 5\% for any of the six wells. However, Table 5 and Fig. 6 show that the absolute percentage deviation between the actual and predicted cumulative CSS oil production per cycle for $42 \%$ of the tested steam cycles (13 out of the 31 steam cycles) is less than or equal $15 \%$. In addition, the absolute percentage deviation between the actual and predicted cumulative CSS oil production per 
cycle for $39 \%$ of tested steam cycles (12 out of the 31 steam cycles) ranges between 15 and $25 \%$. Only $19 \%$ of tested steam cycles ( 6 out of the 31 steam cycles) achieve absolute percentage deviation between the actual and predicted cumulative CSS oil production above $25 \%$.

The prediction results were analyzed to determine the reasons of increasing the percentage deviation for some cycles such as the 6th steam cycle in Well 2 of Buffalo Creek reservoir as shown in Fig. 6b and Table 5A. The actual field conditions were reviewed. It was recognized that steam injection was replaced by hot water injection which led to decrease in the actual oil production in the 6th steam cycle in Well 2 of Buffalo Creek reservoir. The other reasons of the higher deviation might be related to lower pump efficiency, steam production or interference between wells.

\section{Discussion}

The results confirm the validity of the general form of the mathematical relationship to predict the oil production of the CSS wells. Actual CSS field data were compared with the results obtained by the developed mathematical relationship. The developed mathematical relationship predicted 31 steam cycles related to six wells. These wells belong to six reservoirs of different reservoir characteristics. The absolute percentage deviation between the calculated and actual cumulative oil production through the well lifetime ranges between 0 and 5\%. This low error verifies the capability and the strength of the developed mathematical relationship to predict CSS oil production for any case.

The selected cases take into considerations the effects of reservoir characteristics, reservoir dip, cumulative injected steam, total days on production, and number of steam cycles. The reservoir types include fractured carbonate, tight matrix, unconsolidated sandstone, and layered with shale. The field applications include cases of different numbers of CSS cycles (between 4 and 13 cycles). In addition, the total days on production are different from case to case: it reaches up to 1920 days in one of the cases. Also, the field applications include cases with a wide range of the injected steam volume per cycle. The injected steam volume per cycle ranges between 4302 and 88,806 bbl Cold Water Equivalent (CWE).

$90 \%$ of the tested steam cycles ( 28 out of the 31 steam cycles) recorded less than $30 \%$ of the absolute percentage deviation between the actual and predicted cumulative oil production per cycle. The remaining three steam cycles of the tested CSS recorded higher than $30 \%$ of the absolute percentage deviation between the actual and predicted cumulative oil production per cycle. The reason behind that might be related to the following reasons: (1) bad performance of the well pump, (2) inaccurate steam production records or
(3) interference from the surrounding wells. Although the absolute percentage deviation between the actual and calculated oil production per cycle is high in some cases, the predicted cumulative oil production through the well lifetime matches the actual oil production very well (deviation ranges between 0 and $5 \%$ ).

Compared to the other predictive methods, the developed mathematical relationship can deal with different reservoir conditions. The other analytical methods have significant limitations and assumptions. In addition, data unavailability and time limitations along with the uncertainties of the available data in many cases may not support using numerical simulation in prediction. Moreover, the high degree of heterogeneity within the same reservoir does not favor other analogy methods. As shown in the field applications, the developed mathematical relationship was able to deal with different reservoir conditions. Furthermore, the developed mathematical relationship was able to deal with limited available data and limited assumptions. The required data are mainly the petrophysical data and the oil production and steam injection quantities at the end of two previous steam cycles (historical data). The assumptions are mainly the drainage volume and the thermal diffusivity. Therefore, the change in the COSR (Cumulative Oil to Steam Ratio) per day divided by production days has a direct relationship with the effective heating parameters. These parameters are related to the heat injection efficiency. This efficiency is affected by the ratio between the oil net pay thickness to the gross pay thickness, the thermal diffusivity, and the heat losses to the surrounding rocks. Also, the developed mathematical relationship can be presented simply in Log-Log form using dimensionless quantities. This effective and simple mathematical relationship facilitates the method application for any case.

\section{Conclusion}

1. Semi-analytical model was developed to predict the CSS oil production. The model can be applied using injection and production data of two steam cycles in addition to basic petrophysical data.

2. Semi-analytical model was validated using data of six wells from six different reservoirs of varying characteristics and operating conditions. The reservoir data included cases from heterogeneous fractured carbonate reservoirs, low matrix permeability reservoirs, layered unconsolidated sandstone reservoir, and a reservoir with a steep dip.

3. The results showed good match between the predicted and actual cumulative oil production through the well lifetime with average absolute percentage deviation less than $5 \%$ for the six wells. 
4. The absolute instantaneous deviation between the actual and the predicted cumulative oil production for each individual cycle in all cases is (1) less than $15 \%$ for about $42 \%$ of the tested CSS cycles, (2) between 15 to $25 \%$ for about $39 \%$ of the tested CSS cycles, and (3) higher than $25 \%$ for only about $19 \%$ of the tested CSS cycles.

Acknowledgements The authors would like to thank Dr. Mohamed Samir for the valuable discussions with him on the topic.

Funding This work was executed through unfunded research project at Cairo University (Egypt).

Open Access This article is licensed under a Creative Commons Attribution 4.0 International License, which permits use, sharing, adaptation, distribution and reproduction in any medium or format, as long as you give appropriate credit to the original author(s) and the source, provide a link to the Creative Commons licence, and indicate if changes were made. The images or other third party material in this article are included in the article's Creative Commons licence, unless indicated otherwise in a credit line to the material. If material is not included in the article's Creative Commons licence and your intended use is not permitted by statutory regulation or exceeds the permitted use, you will need to obtain permission directly from the copyright holder. To view a copy of this licence, visit http://creativecommons.org/licenses/by/4.0/.

\section{References}

Abou-Kassem J (1996) Practical considerations in developing numerical simulators for thermal recovery. J Pet Sci Eng 15:281-290

Abu El Ela M, Samir M, Sayyoh H, El Tayeb S (2008) Thermal heavy oil recovery projects succeed in Egypt and Syria. Oil Gas J 106:40-45

Ali F, Tamin M (1998) A new analytical cyclic steam stimulation model including formation fracturing. J Can Pet Technol 37:31-40

Alvarez J, Sungyun H (2013) Current overview of cyclic steam injection process. J Pet Sci 2:116-127

Basta G (2020) A new approach to predict the oil wells performance under cyclic steam application. M.Sc. Thesis. Cairo University, Cairo-Egypt. Note: the thesis is under preparation and examination process. It is expected to be awarded in 2020

Boberg TC, Lantz RB (1966) Calculation of the production rate of a thermally stimulated well. J Pet Technol 18:613-623

Ershaghi I, Al-Adawiya MS, Kagawan VD (1983) A graphical method for estimation of production response from cyclic steam stimulation using past performance data. In: SPE-11954-MS, presented at the SPE annual technical conference and exhibition, San Francisco, California, October 5-8

Esmaeili S, Sarma H, Harding T, Maini B (2019) A data-driven model for predicting the effect of temperature on oil-water relative permeability. Fuel J 236:264-277

Faergestad IM (2016) Heavy oil, oilfield reviews. Schlumberger, Paris, France. https://www.slb.com/resource-library/oilfield-review/ defining-series/defining-heavy-oil

Finbow RJ, Koop IJ (1978) A sensitivity study of cyclic steam stimulation using a 2-D mathematical model. J Can Pet Technol 17:58-72

Gontijo JE, Aziz K (1984) A simple analytical model for simulating heavy oil recovery by cyclic steam in pressure-depleted reservoirs.
In: SPE-13037-MS, presented at the SPE annual technical conference and exhibition, Houston, Texas, September 16-19

Jones J (1992) Why cyclic steam predictive models get no respect. SPE Reserv Eng 7:67-74

Jones J (1977) Cyclic steam reservoir model for viscous oil, pressure depleted gravity drainage reservoirs. In: SPE-6544-MS, presented at the SPE California regional meeting, Bakersfield, California, 13-15 April

Kumar M, Beatty FD (1995) Cyclic steaming in heavy oil diatomite. In: SPE-29623-MS, presented at the SPE western regional meeting, Bakersfield, California, 8-10 March

Marquez S, Ghafoori S, Omar M, Almarshed A (2019) Delineation of most efficient recovery technique for typical heavy oil reservoir in the middle east through compositional simulation of temperaturedependent relative permeabilities. J Pet Sci Eng 186:106725

Mozaffari S, Nikookar M, Ehsani MR, Sahranavard L, Roayaie E, Mohammadi AH (2013) Numerical modeling of steam injection in heavy oil reservoirs. Fuel Journal 112:185-192

Mueller TD (1967) A mathematical model of reservoir response during the cyclic injection of steam. Soc Petrol Eng J 7:174-188

PJ Briggs (1989) A simulator for the recovery of heavy oil from naturally fractured reservoirs using cyclic steam injection. In: SPE17954-MS, presented at SPE middle east oil show, Bahrain, 11-14 March

Popa AS and Patel AN (2012) Neural networks for production curve pattern recognition applied to cyclic steam optimization in Diatomite reservoirs. In: SPE-153185-MS, presented at the SPE Western regional meeting, Bakersfield, California, USA

Prats M (1982) Thermal recovery, Volume 7 of the SPE monograph. Society of Petroleum Engineers, New York

Qin K, Jeff M (2013) A Heuristic production model for cyclic steam stimulation in a fractured heavy oil carbonate reservoir. In: SPE165462-MS, presented at the SPE heavy oil conference. Calgary, Alberta, Canada, June 11-13

Rivero RT, Heintz RC (1975) Resteaming time determination-case history of a steam-soak well in Midway Sunset. J Pet Technol 27:665-671

Seba RD, Perry GE (1969) A mathematical model of repeated steam soaks of thick gravity drainage reservoirs. J Pet Technol 21:87-94

Sun Q, Ertekin T (2016) Structure an artificial intelligence-based decision-making tool for cyclic steam stimulation processes. J Pet Sci Eng 154:564-575

Tamim M, Abou-Kassem J, Farouq A (2000) Recent developments in numerical simulation techniques of thermal recovery processes. J Pet Sci Eng 26:283-289

Towson DE, Boberg TC (1967) Gravity drainage in thermally stimulated wells. J Can Pet Technol 6:130-135

Uribe JP, Pinilla JF, Cabrera Montes D (2010) Innovative methodology to revitalize a heavy-oil mature field by Identifying opportunities to apply new cycles of steam injection. In: SPE-138918-MS, presented at the SPE Latin American and caribbean petroleum engineering conference, Lima, Peru, March 21-23

Yang D, Hosseininejad Mohebati M, Brand S, Bennett C (2014) Thermal recovery of bitumen from the Grosmont carbonate formation - part 2: pilot interpretation and development strategy. J Can Pet Technol 53:212-223

Yoelin SD (1971) The TM sand steam stimulation. J Pet Technol 23:987-994

Publisher's Note Springer Nature remains neutral with regard to jurisdictional claims in published maps and institutional affiliations. 